\title{
Effect of three lactobacilli with strain- specific activities on the growth performance, faecal microbiota and ileum mucosa proteomics of piglets
}

Yating Su${ }^{1}$, Xingjie Chen ${ }^{2}$ Ming Liư ${ }^{3}$ and Xiaohua Guo ${ }^{*}$

\begin{abstract}
Background: The beneficial effects of Lactobacillus probiotics in animal production are often strain-related. Different strains from the same species may exert different weight-gain effect on hosts in vivo. Most lactobacilli are selected based on their in vitro activities, and their metabolism and regulation on the intestine based on strainrelated characters are largely unexplored. The objective of the present study was to study the in vivo effects of the three lactobacilli on growth performance and to compare the differential effects of the strains on the faecal microbiota and ileum mucosa proteomics of piglets.
\end{abstract}

Methods: Three hundred and sixty piglets were assigned to one of four treatments, which included an antibioticstreated control and three experimental groups supplemented with the three lactobacilli, L. salivarius G1-1, L. reuteri G8-5 and L. reuteri G22-2, respectively. Piglets were weighed and the feed intake was recorded to compare the growth performance. The faecal lactobacilli and coliform was quantified using quantitative PCR and the faecal microbiota was profiled by denaturing gradient gel electrophoresis (DGGE). The proteomic approach was applied to compare the differential expression of proteins in the ileum mucosa.

Results: No statistical difference was found among the three Lactobacillus-treated groups in animal growth performance compared with the antibiotics-treated group $(P>0.05)$. Supplementation of lactobacilli in diets significantly increased the relative $16 \mathrm{~S}$ rRNA gene copies of Lactobacillus genus on both $\mathrm{d} 14$ and $\mathrm{d} 28(P<0.05)$., and the bacterial community profiles based on DGGE from the lactobacilli-treated groups were distinctly different from the antibiotics-treated group $(P<0.05)$. The ileum mucosa of piglets responded to all Lactobacillus supplementation by producing more newly expressed proteins and the identified proteins were all associated with the functions beneficial for stabilization of cell structure. Besides, some other up-regulated and down-regulated proteins in different Lactobacillus-treated groups showed the expression of proteins were partly strain-related.

Conclusions: All the three lactobacilli in this study show comparable effects to antibiotics on piglets growth performance. The three lactobacilli were found able to modify intestinal microbiota and mucosa proteomics. The regulation of protein expression in the intestinal mucosa are partly associated with the strains administrated in feed.

Keywords: Faecal microbiota, Growth, Lactobacillus, Mucosa proteomics, Probiotics

\footnotetext{
*Correspondence: guo_xh@hotmail.com

${ }^{1}$ Provincial Key Laboratory for Protection and Application of Special Plants in

Wuling Area of China, College of Life Science, South-Central University for

Nationalities, No. 182, Minyuan Road, Hongshan District, Wuhan, Hubei

Province 430074, China

Full list of author information is available at the end of the article
} 


\section{Background}

As living microorganisms, probiotics act in the intestine to modulate the host microbiota [1]. Among the strains of probiotics, lactic acid bacteria (LAB), especially from Lactobacillus and Bifidobacteria species, are recognized as one of the main sources and are widely used in food, drugs and feed additives as intestinal flora improvers [2]. In animal production, probiotics are expected to improve performance and to produce high-qualified meat without drug residues as an alternative to antibiotics [3].

Generally, Lactobacillus species selected for probiotics are highly diverse in the phenotypic and genetic characteristics [4]. Different strains may exert different weight-gain effect on hosts in vivo even if in the same species. Million et al. assessed the effect of lactobacilli-containing probiotics on weight based on 51 studies on farm animals and suggested that the weight-gain effect was greatly associated with strains of the genus [3]. Simon et al. showed similar results after summarizing above 20 published papers on lactobacilli used in feed additives [5]. The phenomena suggest that Lactobacillus strains may benefit their hosts through different mechanisms and more work should be done to explore the relationship between the choice of strains and their in vivo behaviours [6].

Nowadays the selection of Lactobacillus is often based on the strains' activities in vitro, which is expected to show corresponding effectiveness in vivo. The strains with bacteriocin-producing activity showed specific antiinfective effect in the gut [7]. The strains with enzyme activities including amylase, protease and $\alpha$ galactosidase had the potential to stimulate feed digestion [8-10]. However, the gut ecosystem was so complicated and the in vivo activities often depended on the strains' survival and metabolism in the gastrointestinal tract (GIT) [10]. In our previous studies, three Lactobacillus strains (Lactobacillus salivarius G1-1, Lactobacillus reuteri G8-5 and Lactobacillus reuteri G22-2) were selected from swine faeces for probiotic use. They shared strain-related in vitro functional properties, including antimicrobial activity, amylolytic activity and bile-salt-hydrolase activity, respectively [11]. Meanwhile, from the in vivo studies in rats, the three Lactobacillus species showed some similar beneficial effects and some of the functionalities to rats were strain-specific [12]. When used in swine nutrition, the lactobacilli were hypothesized to interact with the intestinal flora and with the host mucosa, which might be associated with the mechanism of lactobacilli as probiotics. The objective of the present study was to study the in vivo effects of the three lactobacilli on growth performance and to compare the differential effects of the strains on the faecal microbiota and ileum mucosa proteomics of piglets.

\section{Methods}

Lactobacillus strains and freeze-dried powder preparation Three strains, $L$. salivarius G1-1, L. reuteri G8-5 and $L$. reuteri G22-2 were isolated for probiotics based on the strain-specific functional properties in vitro [11]. All strains were incubated in DeMan Rogosa Sharp broth under anaerobic conditions at $37^{\circ} \mathrm{C}$ for about $24 \mathrm{~h}$. The microbial cells were collected by centrifugation at $11,000 \times \mathrm{g}$ for $10 \mathrm{~min}$, washed twice and mixed with protective additives for freeze-drying. The freeze-dried sample was smashed and diluted with dextrin as a carrier. The concentration of viable cells from each strain was determined by agar-plate assay and adjusted to $0.5 \times 10^{9}$ colony forming unit per gram (CFU/g) by the carrier before animal trial.

\section{Animals, diets, experimental design and sampling}

Three hundred and sixty castrated male, crossbred (Landrace $\times$ Large White) piglets, 35-40 days old, were randomly assigned to one of four treatments, which included an antibiotics control (Group A) and three experimental groups supplemented with $L$. salivarius G1-1 (Group B), L. reuteri G8-5 (Group C) and L. reuteri G22-2 (Group D), respectively. The piglets were housed with 15 piglets per pen and six pens of piglets received each treatment $(n=6)$. The pigs had free access to feed and water throughout the feeding trial with the environmental temperature $25-28{ }^{\circ} \mathrm{C}$. The diet composition was listed in Table 1. The diet in the antibiotics control was supplemented with $200 \mathrm{mg} / \mathrm{kg}$ flavomycin. The three experimental diets consisted of the basal diet supplemented with $200 \mathrm{mg} / \mathrm{kg}$ Lactobacillus powder $\left(10^{9} \mathrm{CFU} /\right.$ $\mathrm{kg}$ of feed) from each strain.

Piglets were weighed and the feed intake was recorded during the trial term to calculate the average daily weight gain (ADG), average daily feed intake (ADFI) and feed conversion ratio (F:G). Fresh faecal samples (4-5 g) from 3-4 individual piglets were collected and pooled from three randomly chosen pens were collected for each treatment on $\mathrm{d} 14$ and 28 . The samples after collection were immediately stored at $-20{ }^{\circ} \mathrm{C}$ until the molecular analysis for microbiota. At the end of the trial, three randomly chosen piglets were selected from each treatment and slaughtered for ileum sampling. About $20 \mathrm{~cm}$ ileum at the same place of each pig were rapidly cut and the chyme was washed out using sterile water. The mucosa was carefully scrapped by coverslips and kept in $1.5 \mathrm{~mL}$ Eppendorf tube. The samples were frozen immediately by liquid nitrogen and stored at $-80{ }^{\circ} \mathrm{C}$ for proteomics analyses. All surgical and animal care procedures in the study followed the protocols approved by Experimental Animal Care and Use Guidelines (Chinese Science and Technology Committee, 1988). 
Table 1 Basal diet formula and nutrient levels

\begin{tabular}{lcll}
\hline Ingredients & Percentage, \% & Nutrient levels & \\
\hline Extruded corn, soybean and & 30.37 & DE, Mcal/kg & 3.30 \\
sorghum & & & \\
with the proportion (3:1:1) & & & \\
High protein flour & 17.40 & Crude protein, \% & 18.2 \\
Extruded soybean & 5.00 & Crude fat, \% & 5.05 \\
Concentrated soybean meal & 8.00 & Crude ash, \% & 5.69 \\
Limestone & 1.00 & Crude fiber, \% & 1.79 \\
Calcium phosphate & 0.69 & Ca, \% & 0.75 \\
Diamond V XP Yeast Culture & 0.50 & Total & 0.54 \\
& & phosphorus, \% & \\
Mineral premix & 1.50 & Salt, \% & 0.63 \\
Vitamins premix & 1.00 & & \\
Lysine, 98\% & 0.55 & & \\
N-carbamoylglutamate & 0.06 & & \\
Threonine & 0.32 & & \\
Methionine & 0.26 & & \\
Skim milk powder & 7.50 & & \\
Whey powder & 12.50 & & \\
Fatty powder & 3.33 & & \\
Proprietary milk substitute & 5.00 & & \\
Dextrose & 5.00 & & \\
Antibiotics or lactobacilli & 0.02 & & \\
powder & 100.00 & & \\
Total & & & \\
a Vitamins & & \\
\end{tabular}

a Vitamins provided per kilogram diets: vitamin $A, 8000 \mathrm{IU}$; vitamin $D_{3}$, $1800 \mathrm{IU}$; vitamin $\mathrm{E}, 30 \mathrm{IU}$; vitamin $\mathrm{K}_{3}, 3.56 \mathrm{mg}$; vitamin $\mathrm{B}_{1}, 1.8$; vitamin $\mathrm{B}_{2}$, $6 \mathrm{mg}$; vitamin $\mathrm{B}_{6}, 1.26 \mathrm{mg}$; vitamin $\mathrm{B} 1_{2}, 0.02 \mathrm{mg}$; folic acid, $0.3 \mathrm{mg}$; biotin, $0.44 \mathrm{mg}$; niacin, $32 \mathrm{mg}$; pantothenic acid, $15 \mathrm{mg}$

${ }^{b}$ Minerals provided per kilogram diets: $\mathrm{Cu}, 250 \mathrm{mg} ; \mathrm{Fe}, 130 \mathrm{mg} ; \mathrm{Zn}, 130 \mathrm{mg}$; $\mathrm{Mn}, 60 \mathrm{mg}$; Se, $0.3 \mathrm{mg}$; l, $0.4 \mathrm{mg}$

\section{DNA extraction, real-time quantitative PCR and PCR-DGGE} analyses

The total genomic DNA was extracted from faeces (about $1.0 \mathrm{~g}$ ) based on the method of bead-beating and following phenol-chloroform extraction [13, 14]. Total lactobacilli and coliform were detected by real-time quantitative PCR, respectively. The lactobacilli were quantified using primer Lac1 (5' -AGCAGTAGGGAATCTTCCA-3'), and Lab0677 (5' - CACCGCTACACATGGAG -3') [15]. Two primers, EcoliFimH2F (5'-AGCAGTAGGGAATCTTCCA-3') and EcoliFimH2R ( 5 ' - TCATCCCTGTTATAGTTGYYGGTCT$\left.3^{\prime}\right)$ were used to amplify $16 \mathrm{~S}$ rRNA gene of coliform [16]. The reverse transcription PCR (RT-PCR) system was quantified using the ABI 7500 system (Applied Biosystems, US). The optimum thermal cycles were performed as follows: pre-denaturation at $95{ }^{\circ} \mathrm{C}$ for $10 \mathrm{~min}, 40$ cycles of $95{ }^{\circ} \mathrm{C}$ for $15 \mathrm{~s}$ and $60{ }^{\circ} \mathrm{C}$ for $1 \mathrm{~min}$, and followed by the stage of melting curve. The relative $16 \mathrm{~S}$ rRNA gene copies were calculated through the $2^{-\Delta \Delta C T}$ method according to the report of Livak [17]. The results were compared based on the three paralleled values of faeces from each treatment.

A set of universal primers, U968-GC (5'-CGCCCG GGGCGCGCCCCGGGCGGGGCGGGGGCACGGGG GGAACGCGAAGAACCTTAC-3'), L1401 (5' -CGGTGT GTACAAGACCC-3') [18], Bact 1369 F (5'-CGGTGAA TACGTTCYCGG-3'), and 1492R (5'-GGWTACCTT GTTACGACTT-3') [19] were employed to amplify the total bacteria. The amplicons were separated by DGGE according to the specification as described previously [20]. Briefly, DGGE was performed in $8 \%$ polyacrylamide gels (acrylamide-bis, 37.5:1). The gels with a 38-51\% denaturing gradient was used for the separation of PCR products based on the primers U968-GC and L1401, while gradients of $30-45 \%$ were applied for the separation of the Bact $1369 \mathrm{~F}$ and 1492R generated amplicons. The electrophoresis procedures were performed at $70 \mathrm{~V}$ for $16 \mathrm{~h}$ at $60{ }^{\circ} \mathrm{C}$ and the gel was finally stained with SYBR Green I for $30 \mathrm{~min}$ after electrophoresis. The DGGE gels were scanned using an image scanner and analysed with Bio-rad gel imaging system through Quantity One software (Version 4.6.2).

The similarities among DGGE profiles were determined by Dice coefficient based on the unweighted pair group method with arithmetic average (UPGMA) clustering algorithm [21]. The faecal samples from the antibiotics group were evenly mixed and conducted for DGGE profiles used as the control band. The bands from three paralled faecal samples of each Lactobacillus group were profiled and compared with the control band $(n=3)$.

\section{2-dimensional electrophoresis (2-DE), image analysis and protein identification}

Isoelectric focusing (IEF) was performed using immobilized $\mathrm{pH}$ gradient (IPG) Strips ( $\mathrm{pH} 4-7 ; 7$ cm long; Pharmacia Biotech.). Samples were diluted with IEF buffer containing $7 \mathrm{~mol} / \mathrm{L}$ urea, $2 \mathrm{~mol} / \mathrm{L}$ thiourea, 4\% CHAPS, $20 \mathrm{mmol} / \mathrm{L}$ Tris-HCl, pH 8.5, $20 \mathrm{mmol} / \mathrm{L}$ DTT, 0.5\% carrier ampholyte ( $\mathrm{pH} 4-7)$ and a trace of bromophenol blue. The desired protein amount in buffer was $50 \mu \mathrm{g}$. After equilibration, the immobilized $\mathrm{pH}$ gradient strips were loaded onto $12.5 \%(\mathrm{w} / \mathrm{v})$ homogeneous acrylamide gels and sealed with $1 \%(\mathrm{w} / \mathrm{v})$ agarose. The electrophoretic separation of proteins was conducted as described previously [22, 23]. Upon completion of 2-dimensional SDS-PAGE, the gels were stained by silver or Coomassie Brilliant Blue G-250. The high-resolution gel images (200 dpi) from silver-stained gels were obtained using an image scanner (Powerlook1100, UMAX) for image analysis. The gels stained by silver were run in triplicate, and spots that appeared consistently in all three runs were selected for analysis. Spot detection and analysis were performed using the PDQuest version 6.1 software (Bio-Rad) according to the protocols provided by the 
manufacturer. Some differentially expressed protein spots with 3.0-fold differences in volume detected by the software were selected for protein identification. The protein spots of interest were confirmed in the Coomassie Brilliant Blue stained gels and manually excised for the treatment of digestion by trypsin. The matrix-assisted laser desorption/ionization time of flight mass spectrometry (MALDI-TOF MS) was used for protein identification as described by early reports $[24,25]$. The peptide fragments produced from each protein spot were employed to produce peptide-mass mapping (PMM) data. The protein identification was carried out by peptide mass fingerprinting (PMF) analysis through the MASCOT server (www.matrixscience.com; Matrix Science, UK). The search parameters were as follows, database: Swiss-Prot Sus (34361 sequences); species: sus; enzyme: trypsin; fixed modifications: carbamidomethylation; variable modifications: oxidation $(\mathrm{M})$. The gene name, accession code and function of each protein were determined using the Mascot V2.1 software protein database search engine and the Swiss-Prot Sus protein database.

\section{Statistical analyses}

All quantitative data were expressed as the mean and standard deviation of replicates. The differences among antibiotics-treated and lactobacilli-treated groups were considered statistically significant at $P<0.05$ using one-way analysis of variance (One-way ANOVA) through JMP software (JMP; SAS Institute Inc., Cary, NC). $0.5<P<0.1$ was considered a trend towards significance.

\section{Results}

\section{Growth performance}

Over the 4-week feeding trial, there was no statistical difference in ADG, ADFI and F:G between piglets supplemented with lactobacilli and the antibiotics group (Table 2). Among the three Lactobacillus groups, the diet containing L. reuteri G8-5 tended to show lower ADG and ADFI than that of the other two Lactobacillus groups $(0.5<P<0.1)$.

\section{Relative 16S rRNA gene copies by RT-PCR}

A comparison of the relative 16S rRNA gene copies of Lactobacillus and coliform in faeces on d 14 and d 28 was shown in Fig. 1. Supplementation of lactobacilli in diets significantly increased the counts of Lactobacillus genus on both d 14 and d 28 compared with the antibiotics group $(P<0.05)$. However, no significant difference in the relative $16 \mathrm{~S}$ rRNA gene copies of coliform was observed in all groups $(P>0.05)$.

\section{PCR-DGGE profiles}

The representative DGGE profiles were presented in Fig. 2. The DGGE patterns were transformed into graphs by the Bio-Rad Quantity One ${ }^{\mathrm{TM}}$ software, which calculated the Dice similarity among lanes (Fig. 2). The similarities among four treatments on d 14 and d 28 were listed in Table 3. On $\mathrm{d} 14$, the dendrogram based on the banding patterns showed low similarities and the bacterial community profiles form the lactobacilli were distinctly different from the antibiotics group $(P<0.05)$. Meanwhile, the similarities in $L$. reuteri G8-5 group were significantly lower than those in $L$. salivarius G1-1 group $(P<0.05)$. On $\mathrm{d}$ 28, the percentage of similarity in all Lactobacillus groups increased but was still significantly lower than that of antibiotics group. There was no marked difference in similarities in all Lactobacillus-treated groups on d 28 $(P>0.05)$.

\section{2-DE profiles of differentially expressed proteins}

By comparing the 2-DE profiles of differentially expressed proteins in the ileum of piglets between the antibiotics-treated and Lactobacillus-treated groups, supplementation of lactobacilli significantly increased the counts of newly expressed proteins. 4, 6 and 8 new proteins were expressed only in the antibiotics group compared with the three Lactobacillus groups, respectively. Nevertheless, 32, 40 and 27 new proteins only existed in the three Lactobacillus groups compared with the antibiotics group, respectively (Fig. 3a). Among the differentially expressed proteins, 4 protein spots which were up-regulated in all the Lactobacillus-treated groups were selected for the identification by MALDI-TOF.

Table 2 The effect of three lactobacilli on the growth performance of weaned piglets during a 4-week feeding trial

\begin{tabular}{|c|c|c|c|c|c|c|c|c|c|c|}
\hline \multirow[t]{2}{*}{ Treatments } & \multirow{2}{*}{$\begin{array}{l}\text { Antibiotics } \\
\text { (A) }\end{array}$} & \multirow{2}{*}{$\begin{array}{l}\text { L. salivarius } \\
\text { G1-1 (B) }\end{array}$} & \multirow{2}{*}{$\begin{array}{l}\text { L. reuteri } \\
\text { G8-5 (C) }\end{array}$} & \multirow{2}{*}{$\begin{array}{l}\text { L. reuteri } \\
\text { G22-2 (D) }\end{array}$} & \multicolumn{6}{|l|}{$P$-value } \\
\hline & & & & & A vs. B & A vs. C & A vs. D & B vs. C & B vs. D & C vs. D \\
\hline Initial body weight, kg & $7.44 \pm 1.22$ & $7.51 \pm 1.00$ & $7.56 \pm 0.92$ & $7.51 \pm 0.92$ & 0.913 & 0.871 & 0.922 & 0.957 & 0.992 & 0.949 \\
\hline Final body weight, kg & $14.48 \pm 1.19$ & $14.81 \pm 0.56$ & $13.88 \pm 1.13$ & $14.71 \pm 1.87$ & 0.727 & 0.516 & 0.807 & 0.325 & 0.916 & 0.376 \\
\hline$A D G, g / d$ & $270.9 \pm 17.1$ & $280.3 \pm 20.5$ & $243.3 \pm 15.8$ & $276.9 \pm 38.8$ & 0.603 & 0.141 & 0.743 & 0.056 & 0.846 & 0.080 \\
\hline$A D F I, g / d$ & $408.6 \pm 33.4$ & $422.8 \pm 15.4$ & $338.5 \pm 36.9$ & $418.1 \pm 20.5$ & 0.486 & 0.331 & 0.639 & 0.109 & 0.817 & 0.161 \\
\hline$F: G$ & $1.51 \pm 0.13$ & $1.51 \pm 0.08$ & $1.60 \pm 0.09$ & $1.54 \pm 0.11$ & 0.976 & 0.338 & 0.859 & 0.337 & 0.872 & 0.420 \\
\hline
\end{tabular}

Values are means \pm S.D, $n=6$ 

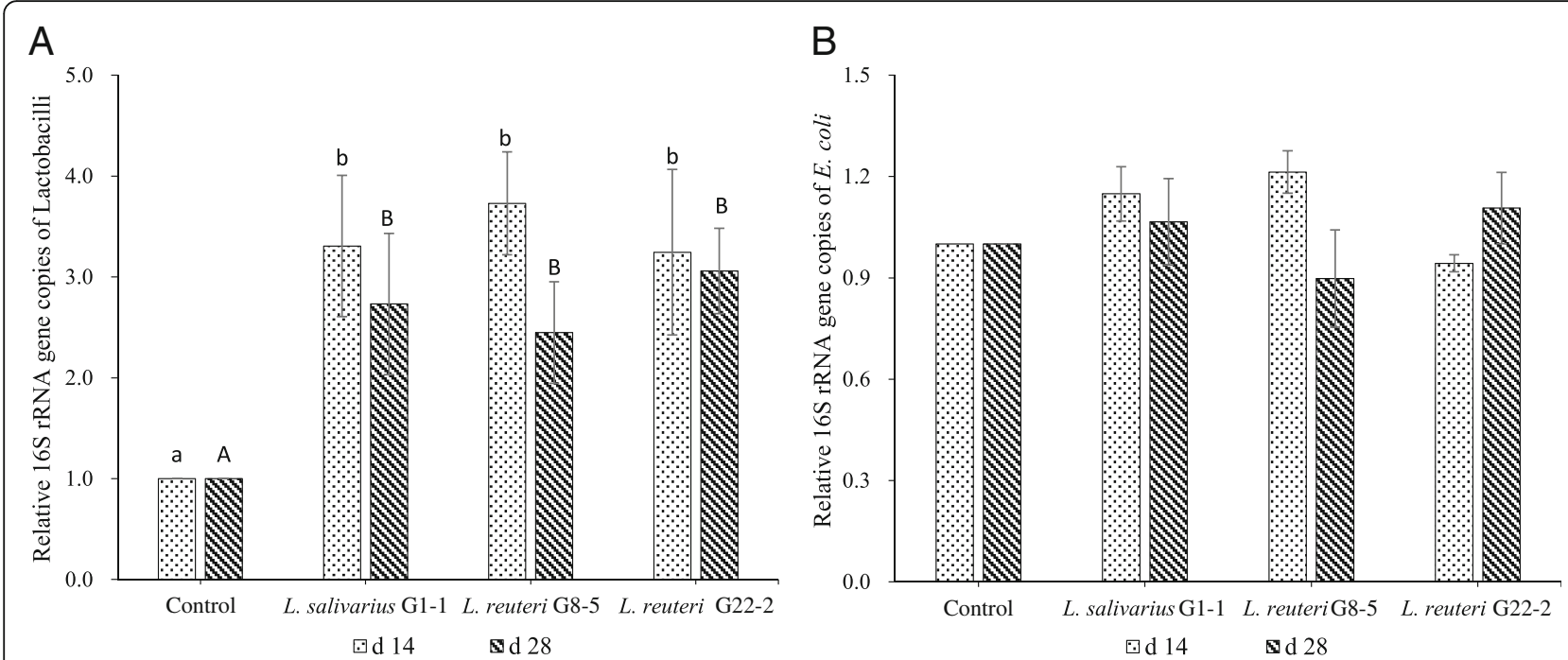

Fig. 1 Effect of three Lactobacillus strains on the fecal relative 16S rRNA gene copies of lactobacilli (a) and E. coli (b), respectively on d 14 and d 28. ${ }^{\text {ab }}$ mean in the same column from the result on $d 14$ with different scripts differ significantly $(P<0.05) ;{ }^{A B}$ means in the same column from the result on d 28 with different scripts differ significantly $(P<0.05)$

These proteins included tropomyosin beta chain (TPM2, Spot R1), vimentin (VIM, Spot R2), keratin type I cytoskeletal 19 (KRT19, Spot R3), tropomyosin alpha-1 chain (TPM1, Spot R4) (Table 4; Fig. 3b). Other six protein spots were chosen because they were specifically affected by different Lactobacillus strains (Table 4; Fig. 3c). The proteins in $L$. salivarius G1-1 group included the upregulation of phosphatidylinositol 4,5-bisphosphate 3-kinase catalytic subunit gamma isoform (PIK3CG, Spot UB1) and cofilin-1 (CFL1, Spot UB2), which were only detectable in L. salivarius G1-1-treated group. The proteins expressed in $L$. reuteri G8-5 group included the up-regulation of Rho GDP-dissociation inhibitor 2 (ARHGDIB, Spot $\mathrm{UC1}$; only detectable in lactobacilli group) and the down-regulation of nucleophosmin (NPM1, Spot UC2). The proteins in L. reuteri G22-2 group included the up-regulation of Rho GDP-dissociation inhibitor 2 (ARHGDIB, Spot UD1; only detectable in

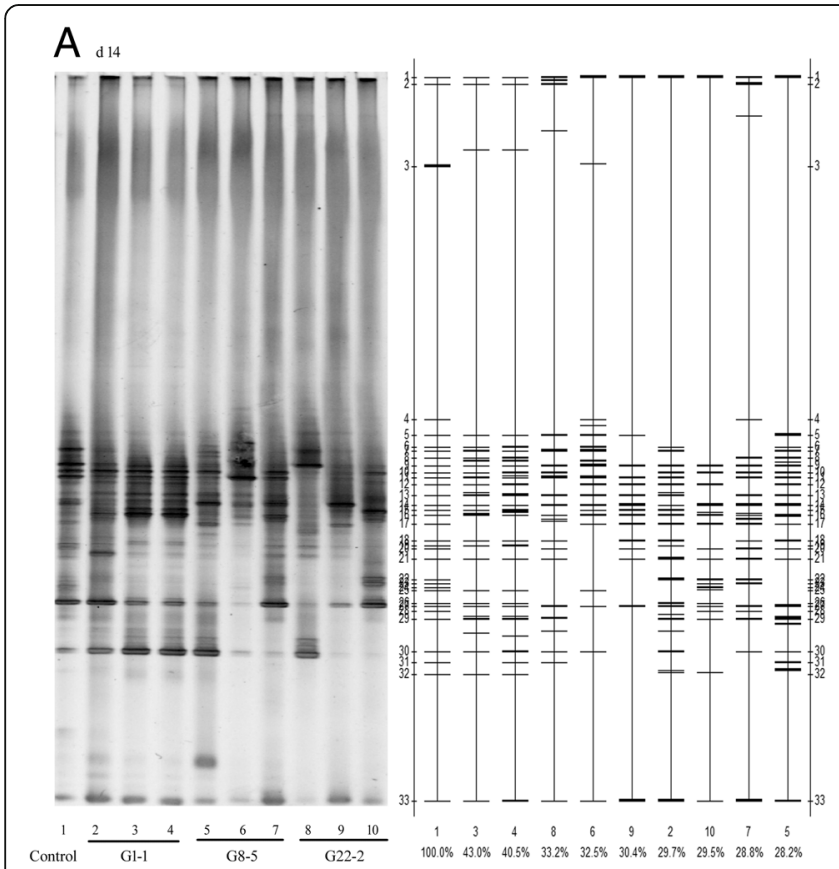

$\mathrm{B}_{\mathrm{d} 28}$

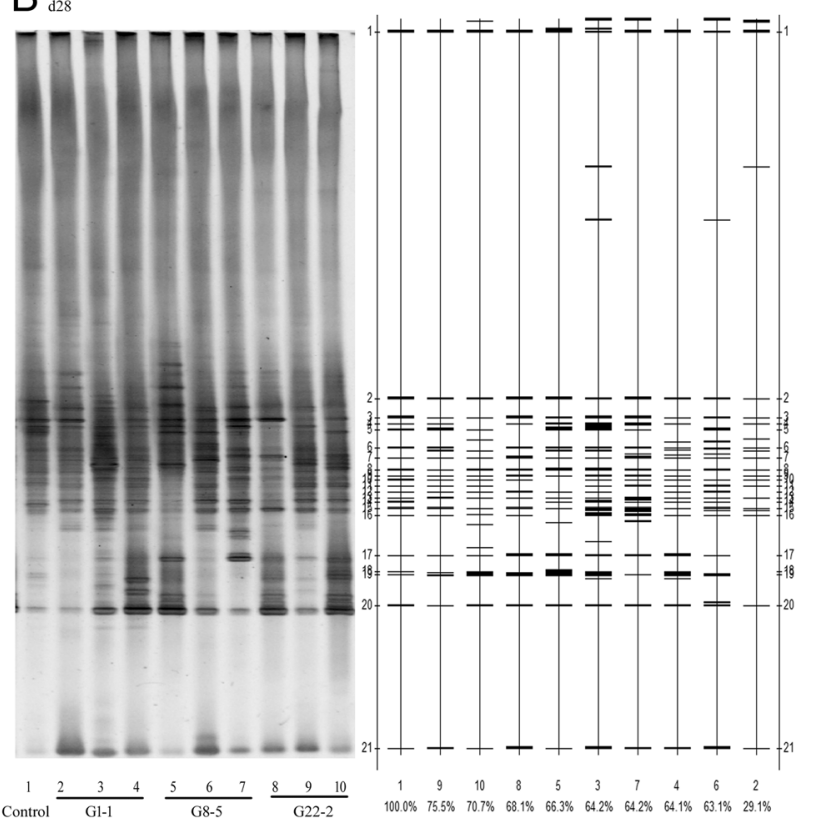

Fig. 2 PCR-DGGE DNA profiles of the 16S rRNA of microbiota in faces of weaned pigs at d 14 (a) and d 28 (b) during a 4-week feeding trial 
Table 3 Effect of three Lactobacillus strains on the similarities among digitalized DGGE profiles of PCR-amplified $16 \mathrm{~S}$ rRNA from fecal DNA after Bio-Rad Quantity One software comparison

\begin{tabular}{lll}
\hline & Similarity, \% & \\
\hline Treatments & d 14 & d 28 \\
Antibiotics & $100.00 \pm 0.00^{\mathrm{a}}$ & $100.00 \pm 0.00^{\mathrm{a}}$ \\
L. salivarius G1-1 & $37.73 \pm 7.07^{\mathrm{b}}$ & $52.47 \pm 20.24^{\mathrm{b}}$ \\
L. reuteri G8-5 & $29.83 \pm 2.33^{\mathrm{c}}$ & $64.53 \pm 1.63^{\mathrm{b}}$ \\
L. reuteri G22-2 & $31.03 \pm 1.93^{\mathrm{bc}}$ & $71.43 \pm 3.75^{\mathrm{b}}$ \\
\hline
\end{tabular}

Values are means $\pm S . D, n=3$. ${ }^{\text {a }}$ b, c Mean in a same column with different superscripts differ significantly $(P<0.05)$

lactobacilli-treated group) and the down-regulation of actin cytoplasmic 1 (ACTB, UD2; only detectable in antibiotics group).

\section{Discussion}

The supplementation of lactobacilli in animal diets affects gastrointestinal tract health and growth performance of piglets $[1,5]$. However, different Lactobacillus strains used as probiotics may achieve the beneficial effects on hosts through different mechanisms [12, 26]. The present study was conducted to compare the different efficacies among three lactobacilli with strainspecific activities in growth performance, faecal microbiota and ileum mucosa proteomics of piglets.

No significant differences in growth performance among Lactobacillus-treated groups were observed compared with the antibiotics-treated group. The result showed that all the three lactobacilli had the same potential as alternative to antibiotics in feed. However, among the three lactobacilli, the supplementation of $L$. reuteri G8-5 was the least effective in enhancing the growth performance of piglets, which was in line with the previous study in the rat experiment [12]. The reason is probably associated with the strain's lower antimicrobial activity compared with the other two strains, which was reported in the previous study [11].

Increased lactobacilli in faeces from lactobacilli-treated piglets on both d 14 and d 28 in this study verified the ability of the three lactobacilli to maintain the balance of microbiota, which was one of the possible mechanisms of lactobacilli as probiotics in vivo [27]. Meanwhile, the modulation of intestinal microbiota by lactobacilli might be strain-insensitive since all the three lactobacilli used in the study showed the same ability as intestinal flora improvers. No difference in coliform counts was observed in whole feeding period compared with the antibiotics group. The result suggested the antibiotics used in the study and lactobacilli had the similar resistance to pathogens and kept them in low level in the gastrointestinal tract. It is assumed that the increasing intestinal microbial abundance caused by antibiotics or lactobacilli has more power to resist the disruption of microbial balance $[28,29]$. Further analysis on the microbiota in the gastrointestinal tract treated by lactobacilli and antibiotics by PCR-DGGE was investigated for the comparison

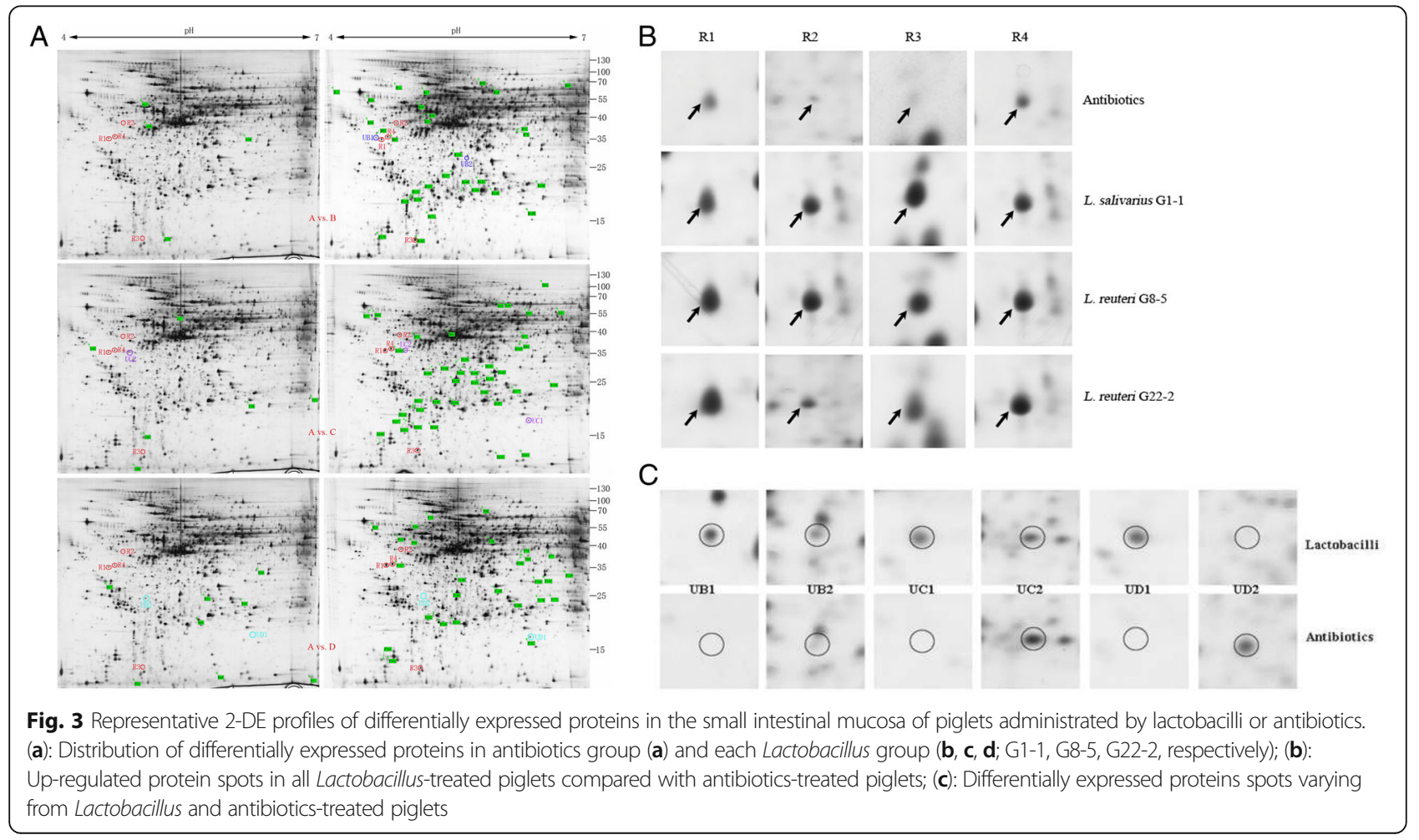


Table 4 Differentially expressed proteins in the ileum mucosa of piglets supplemented by three lactobacilli in diets compared with antibiotics

\begin{tabular}{|c|c|c|c|c|c|c|c|}
\hline Category & Spot No. ${ }^{a}$ & Gene & Accession code & Protein & $\begin{array}{l}\text { Expression change } \\
\text { (Lactobacilli VS. Antibiotics) }\end{array}$ & Score $^{b}$ & Putative function \\
\hline \multirow{4}{*}{$\begin{array}{l}\text { Lactobacilli-insensitive } \\
\text { spots compared } \\
\text { with antibiotics }\end{array}$} & $\mathrm{R} 1$ & TPM2 & F1SG00 & $\begin{array}{l}\text { Tropomyosin } \\
\text { beta chain }\end{array}$ & Up-regulation & 261 & $\begin{array}{l}\text { Stabilizing cytoskeleton } \\
\text { actin filaments }\end{array}$ \\
\hline & $\mathrm{R} 2$ & VIM & P02543 & Vimentin & Up-regulation & 138 & $\begin{array}{l}\text { Maintaining cell shape, } \\
\text { integrity of the cytoplasm, } \\
\text { and stabilizing cytoskeletal } \\
\text { interactions }\end{array}$ \\
\hline & R3 & KRT19 & F1S0J8 & $\begin{array}{l}\text { Keratin type I } \\
\text { cytoskeletal } 19\end{array}$ & Up-regulation & 185 & $\begin{array}{l}\text { Maintaining structural } \\
\text { integrity of epithelial cells }\end{array}$ \\
\hline & R4 & TPM1 & F2Z5B6 & $\begin{array}{l}\text { Tropomyosin } \\
\text { alpha-1 chain }\end{array}$ & Up-regulation & 277 & $\begin{array}{l}\text { Stabilizing cytoskeleton } \\
\text { actin filaments }\end{array}$ \\
\hline \multirow[t]{6}{*}{$\begin{array}{l}\text { Lactobacilli-related } \\
\text { spots compared } \\
\text { with antibiotics }\end{array}$} & UB1(G1-1) & PIK3CG & О02697 & $\begin{array}{l}\text { Phosphatidylinositol } \\
\text { 4,5-bisphosphate } \\
\text { 3-kinase catalytic subunit }\end{array}$ & Only detectable in lactobacilli & 137 & $\begin{array}{l}\text { Maintaining structural } \\
\text { and functional integrity } \\
\text { of epithelia }\end{array}$ \\
\hline & UB2(G1-1) & $C F L 1$ & P10668 & Cofilin-1 & Only detectable in lactobacilli & 121 & $\begin{array}{l}\text { Regulation of cell morphology } \\
\text { and cytoskeletal organization }\end{array}$ \\
\hline & UC1(G8-5) & $A R H G D I B$ & F1SQW8 & $\begin{array}{l}\text { Rho GDP-dissociation } \\
\text { inhibitor } 2\end{array}$ & Only detectable in lactobacilli & 109 & $\begin{array}{l}\text { Small GTPase regulator } \\
\text { activity receptor binding; }\end{array}$ \\
\hline & UC2(G8-5) & NPM1 & F1RRY2 & Nucleophosmin & Down-regulation & 99 & $\begin{array}{l}\text { Ribosome biogenesis } \\
\text { and transport }\end{array}$ \\
\hline & UD1(G22-2) & $A R H G D I B$ & F1SQW8 & $\begin{array}{l}\text { Rho GDP-dissociation } \\
\text { inhibitor } 2\end{array}$ & Only detectable in lactobacilli & 116 & $\begin{array}{l}\text { Small GTPase regulator } \\
\text { activity receptor binding; }\end{array}$ \\
\hline & UD2(G22-2) & ACTB & Q6QAQ1 & Actin cytoplasmic 1 & Only detectable in antibiotics & 139 & $\begin{array}{l}\text { Involved in cell motility, } \\
\text { structure, and integrity }\end{array}$ \\
\hline
\end{tabular}

a Spot No. refers to protein spot numbers that were labeled in Fig. 3

b Protein score generated by MS identification platform MASCOT; a score $>65$ is considered significant

of microbial diversity. On d 14 and d 28, the similarities in all Lactobacillus-treated groups were significantly different from the antibiotics-treated group. The results suggested that the mechanisms of antibiotics and lactobacilli on regulating intestinal microbiota were through different ways and lactobacilli contributed to comparatively complex bacterial community. Some similar results were also shown in other reports [30, 31]. The results in Table 4 and Fig. 2 showed the discrepancy in similarities between lactobacilli and antibiotics treatments tended to decrease from $\mathrm{d} 14$ to $\mathrm{d} 28$. This indicates the bacterial diversity tended to be stable and not sensitive to extraneous drugs or introduced bacteria during animals' growth. The significantly lower Dice similarity in L. reuteri G8-5 compared with L. salivarius G1-1 was observed in this study, and the result was in line with that in the growth performance.

Proteomics play an important role in the assessment of specific health-promoting activities exerted by Lactobacillus species [32, 33]. The ileum mucosa samples were collected to compare the differentially expressed proteins through 2-DE profiles. From the result in Table 4, the supplementation of lactobacilli all greatly increased the number of expressed protein spots compared with the antibiotics group. Similar result was also observed in the study of Wang et al. [32]. Up-regulation of four proteins including TPM2, VIM, KRT19 and TPM1 in all three Lactobacillus groups are all associated with the functions of maintaining and stabilizing cell structure and stabilization. The four proteins were inferred to be Lactobacillus-insensitive, and the mutual mechanisms for Lactobacillus as probiotics were to enhance the expression of proteins beneficial for stabilization of cell structure. Both TPM1 and TPM2 bind to actin filaments and up-regulation of the two proteins benefit to stabilizing cytoskeleton actin filaments [34]. Meanwhile, increased level of VIM is responsible for maintaining cell shape, integrity of the cytoplasm, and stabilizing cytoskeletal interactions [35]. The upregulation of KRT19 is responsible for the structural integrity of epithelial cells [36]. The increased expression of KRT19 in lactobacilli groups can contribute to more opportunities for living cells to adhere to the epithelial and exclusively inhibit pathogen infection [37, 38]. Similar result was also observed in the study of Wang et al. [32], in which KRT10 was higher in the intestinal mucosa of piglets supplemented with L. fermentum 15007 compared with that in antibiotics piglets [32]. Both KRT10 and KRT19 belong to the keratin family which are intermediate filament proteins responsible for the structural integrity of epithelial cells [36].

There were six extra proteins differently expressed in different Lactobacillus groups, which were inferred to be Lactobacillus-related. The different expression of protein might be caused by the characters of specific strains. In the groups of L. salivarius G1-1, two proteins, PIK3CG 
and CFL1, detected only in Lactobacillus group were also associated with cell structure and stability.

ARHGDIB was only detectable in the ileum mucosa of piglets in response to the supplementation of both $\mathrm{L}$. reuteri G8-5 and L. reuteri G22-2. The high expression of the protein enhances the recycling and distribution of activated Rho GTPases in the cell and play a role in regulating cell motility through the modulation of Rho proteins [39]. NPM1 help cells survive environmental stresses, such as drug attack [40]. Up-regulation of NPM1 in antibiotics might be associated with the intake of flavomycin. The increase in ACTB found in vivo would indicate drastic oxidative modification leading to functional impairments [41], which might be the side-effect of antibiotics supplemented in feed. More experiments are needed in order to document the potential beneficial effects of the lactobacilli strains for the piglets, notably in terms of mucosal health.

\section{Conclusions}

In conclusion, this study provides a comprehensive comparison of three lactobacilli with strain-specific activities through the supplementation in piglet diets. All the three lactobacilli show the potential as alternatives to antibiotics and no statistical difference in animal growth performance compared with the antibiotics group. Supplementation of lactobacilli in diets could significantly increase the relative $16 \mathrm{~S}$ rRNA gene copies of lactobacilli genus on both d 14 and d 28, and the bacterial community profile based on PCR-DGGE from the lactobacilli are distinctly different from the antibiotics group. The ileum mucosa piglets respond to all lactobacilli supplementation by more newly expressed proteins and the identified proteins are all associated with the functions beneficial for stabilization of cell structure. Besides, some other up-regulated and down-regulated proteins in different Lactobacillus groups showed the expression of proteins were partly strain-related.

This comparative study helps to explore the mutual mechanisms for Lactobacillus as probiotics on altering intestinal abundance of microbiota and expression of mucosa proteins in piglets and provides information for strain-specific screening in application.

\footnotetext{
Abbreviations

2-DE: 2-dimensional electrophoresis; ACTB: Actin cytoplasmic 1; ADFI: Average daily feed intake; ADG: Average daily weight gain; ARHGDIB: Rho GDP-dissociation inhibitor 2; CFU: Colony forming unit; DGGE: Denaturing gradient gel electrophoresis; DNA: Deoxyribose nucleic acid; F:G: Feed conversion Ratio; GIT: Gastrointestinal tract; IEF: Isoelectric focusing; IPG: Immobilized pH gradient; KRT19: Keratin type I cytoskeletal 19; LAB: Lactic acid bacteria; MALDI-TOF MS: Matrix-assisted laser desorption/ ionization time of flight mass spectrometry; NPM1: Nucleophosmin; PCR: Polymerase chain reaction; PIK3CG: Phosphatidylinositol 4,5bisphosphate 3-kinase catalytic subunit gamma isoform; PMF: Peptide mass fingerprinting; PMM: Peptide-mass mapping; rRNA: Ribosomal ribonucleic acid; RT-PCR: Reverse transcription-polymerase chain reaction; SDSPAGE: Sodium dodecyl sulfate-polyacrylamide gel electrophoresis; TPM1: Tropomyosin alpha-1 chain; TPM2: Tropomyosin beta chain;
}

UPGMA: Unweighted pair group method with arithmetic average; VIM: Vimentin

\section{Acknowledgements}

We would like to thank Jingjing Yang, Huang Ren and Xiaoping Fu for their lab analysis.

\section{Funding}

This work was financially supported by the National Natural Science Foundation of China (No. 31372348; No. 31672455) and the Fundamental Research Funds for the Central Universities (CZY15026).

\section{Availability of data and materials}

The datasets generated during and/or analysed during the current study are available from the corresponding author on reasonable request.

\section{Authors' contributions}

XHG was involved in the study design, data analysis, interpretation and drafting the manuscript; YTS participated in all laboratory analyses; XJC and $\mathrm{ML}$ performed the animal management. All authors read and approved the final manuscript.

\section{Competing interests}

The authors declare that they have no competing interests.

\section{Consent for publication}

All authors read and approved the final manuscript.

\section{Ethics approval}

All procedures for this study followed the protocols approved by Experimental Animal Care and Use Guidelines and approved by Ethical Committee of College of Life Science of South-Central University for Nationalities.

\section{Author details}

${ }^{1}$ Provincial Key Laboratory for Protection and Application of Special Plants in Wuling Area of China, College of Life Science, South-Central University for Nationalities, No. 182, Minyuan Road, Hongshan District, Wuhan, Hubei Province 430074, China. ${ }^{2}$ Guangxi Yang-Xiang Animal Husbandry Co. Ltd, Guigang, Guangxi Province 537100, China. ${ }^{3}$ Beijing China-agri Hong-Ke Biotechnology Co., Ltd., Beijing 102206, China.

Received: 13 March 2017 Accepted: 18 May 2017

Published online: 09 June 2017

\section{References}

1. Fuller R, Gibson GR. Modification of the intestinal microflora using probiotics and prebiotics. Scand J Gastroenter. 1997;32:28-31.

2. Naidu A, Bidlack W, Clemens R. Probiotic spectra of lactic acid bacteria (LAB). Crit Rev Food Sci. 1999;39:13-126.

3. Million M, Angelakis E, Paul M, Armougom F, Leibovici L, Raoult D. Comparative meta-analysis of the effect of Lactobacillus species on weight gain in humans and animals. Microb Pathog. 2012;53:100-8.

4. Klaenhammer TR. Functional activities of Lactobacillus probiotics: genetic mandate. Int Dairy J. 1998;8:497-505.

5. Simon O, Jadamus A, Vahjen W. Probiotic feed additives-effectiveness and expected modes of action. J Anim Feed Sci. 2001;10:51-67.

6. Abbott A. Microbiology: gut reaction. Nature. 2004:427:284-6.

7. Corr SC, Li Y, Riedel CU, O'Toole PW, Hill C, Gahan CG. Bacteriocin production as a mechanism for the antiinfective activity of Lactobacillus salivarius UCC118. P Natl Acad Sci USA. 2007;104:7617-21.

8. Lee H, Gilliland S, Carter S. Amylolytic cultures of Lactobacillus acidophilus: potential probiotics to improve dietary starch utilization. J Food Sci. 2001;66:338-44.

9. LeBlanc JG, Piard JC, Sesma F, de Giori GS. Lactobacillus fermentum CRL 722 is able to deliver active a-galactosidase activity in the small intestine of rats. FEMS Microbiol Lett. 2005;248:177-82.

10. Oozeer R, Goupil-Feuillerat N, Alpert CA, Van de Guchte M, Anba J, Mengaud J, et al. Lactobacillus casei is able to survive and initiate protein synthesis during its transit in the digestive tract of human flora-associated mice. Appl Environ Microbiol. 2002;68:3570-4. 
11. Guo XH, Kim JM, Nam HM, Park SY, Kim JM. Screening lactic acid bacteria from swine origins for multistrain probiotics based on in vitro functional properties. Anaerobe. 2010;16:321-6.

12. Guo XH, Zhao ZD, Nam HM, Kim JM. Comparative evaluation of three Lactobacilli with strain-specific activities for rats when supplied in drinking water. Anton Leeuw Int J G. 2012;102:561-8.

13. Zoetendal EG, Akkermans AD, De Vos WM. Temperature gradient gel electrophoresis analysis of $16 \mathrm{~S}$ rRNA from human fecal samples reveals stable and host-specific communities of active bacteria. Appl Environ Microbiol. 1998;64:3854-9.

14. Su Y, Yao W, Perez-Gutierrez ON, Smidt H, Zhu WY. 16 S ribosomal RNA-based methods to monitor changes in the hindgut bacterial community of piglets after oral administration of Lactobacillus sobrius S1. Anaerobe. 2008;14:78-86.

15. Su Y, Yao W, Perez-Gutierrez ON, Smidt H, Zhu WY. Changes in abundance of Lactobacillus spp. and Streptococcus suis in the stomach, jejunum and ileum of piglets after weaning. FEMS Microbiol Ecol. 2008;66:546-55.

16. Li J, Wang J, Wang F, Wang A, Yan P. Evaluation of gaseous concentrations, bacterial diversity and microbial quantity in different layers of deep litter system. Asian Australas J Anim Sci. 2016;30:275-83.

17. Livak KJ, Schmittgen TD. Analysis of relative gene expression data using realtime quantitative $P C R$ and the $2^{-\Delta \Delta C T}$ method. Methods. 2001;25:402-8.

18. Nübel U, Engelen B, Felske A, Snaidr J, Wieshuber A, Amann Rl, et al. Sequence heterogeneities of genes encoding 165 rRNAs in Paenibacillus polymyxa detected by temperature gradient gel electrophoresis. J Bacteriol. 1996;178:5636-43.

19. Suzuki MT, Taylor LT, DeLong EF. Quantitative analysis of small-subunit rRNA genes in mixed microbial populations via 5'-nuclease assays. Appl Environ Microbiol. 2000;66:4605-14.

20. Muyzer G, de Waal EC. Determination of the genetic diversity of microbial communities using DGGE analysis of PCR-amplified 165 rDNA. Microbial Mats. 1994;35:207-14.

21. Wu X, Ma C, Han L, Nawaz M, Gao F, Zhang X, et al. Molecular characterisation of the faecal microbiota in patients with type II diabetes. Curr Microbiol. 2010;61:69-78

22. Echan LA, Tang HY, Ali-Khan N, Lee K, Speicher DW. Depletion of multiple high-abundance proteins improves protein profiling capacities of human serum and plasma. Proteomics. 2005;5:3292-303.

23. Izquierdo $E$, Horvatovich $P$, Marchioni $E$, Aoude-Werner $D$, Sanz $Y$, Ennahar S. 2-DE and MS analysis of key proteins in the adhesion of Lactobacillus plantarum, a first step toward early selection of probiotics based on bacterial biomarkers. Electrophoresis. 2009:30:949-56.

24. Cordero H, Morcillo P, Cuesta A, Brinchmann MF, Esteban MA. Differential proteome profile of skin mucus of gilthead seabream (Sparus aurata) after probiotic intake and/or overcrowding stress. J Proteomics. 2016;132:41-50.

25. Yang F, Wang J, Li X, Ying T, Qiao S, Li D, et al. 2-DE and MS analysis of interactions between Lactobacillus fermentum 15007 and intestinal epithelial cells. Electrophoresis. 2007:28:4330-9.

26. Du Toit M, Franz C, Dicks L, Schillinger U, Haberer P, Warlies B, et al. Characterisation and selection of probiotic lactobacilli for a preliminary minipig feeding trial and their effect on serum cholesterol levels, faeces $\mathrm{pH}$ and faeces moisture content. Int J Food Microbiol. 1998:40:93-104.

27. Brashears M, Jaroni D, Trimble J. Isolation, selection, and characterization of lactic acid bacteria for a competitive exclusion product to reduce shedding of Escherichia coli 0157: H7 in cattle. J Food Prot. 2003;66:355-63.

28. Wohlgemuth S, Haller D, Blaut M, Loh G. Reduced microbial diversity and high numbers of one single Escherichia coli strain in the intestine of colitic mice. Environ Microbiol. 2009;11:1562-71.

29. Kim HB, Borewicz K, White BA, Singer RS, Sreevatsan S, Tu ZJ, et al. Microbial shifts in the swine distal gut in response to the treatment with antimicrobial growth promoter, tylosin. P Natl Acad Sci USA. 2012;109:15485-90.

30. Sung V, Hiscock H, Tang ML, Mensah FK, Nation ML, Satzke C, et al. Treating infant colic with the probiotic Lactobacillus reuteri: double blind, placebo controlled randomised trial. BMJ. 2014;348:92107

31. Pieper R, Janczyk P, Urubschurov V, Hou Z, Korn U, Pieper B, et al. Effect of Lactobacillus plantarum on intestinal microbial community composition and response to enterotoxigenic Escherichia coli challenge in weaning piglets. Livest Sci. 2010;133:98-100.

32. Wang X, Yang F, Liu C, Zhou H, Wu G, Qiao S, et al. Dietary supplementation with the probiotic Lactobacillus fermentum 15007 and the antibiotic aureomycin differentially affects the small intestinal proteomes of weanling piglets. J Nutr. 2012;142:7-13.
33. Ruiz L, Hidalgo C, Blanco-Míguez A, Lourenço A, Sánchez B, Margolles A. Tackling probiotic and gut microbiota functionality through proteomics. J Proteomics. 2016;147:28-39.

34. Perry SV. Vertebrate tropomyosin: distribution, properties and function. J Muscle Res Cell M. 2001;22:5-49.

35. Wang N, Stamenovic D. Mechanics of vimentin intermediate filaments. J Muscle Res Cell M. 2002;23:535-40.

36. Bragulla $\mathrm{HH}$, Homberger DG. Structure and functions of keratin proteins in simple, stratified, keratinized and cornified epithelia. J Anat. 2009:214:516-59.

37. Dhanani AS, Bagchi T. Lactobacillus plantarum CS24. 2 prevents Escherichia coli adhesion to HT-29 cells and also down-regulates enteropathogeninduced tumor necrosis factor- $a$ and interleukin-8 expression. Microbiol Immunol. 2013;57:309-15.

38. Li X, Yue L, Guan X, Qiao S. The adhesion of putative probiotic lactobacilli to cultured epithelial cells and porcine intestinal mucus. J Appl Microbiol. 2008;104:1082-91.

39. Garcia-Mata R, Boulter E, Burridge K. The 'invisible hand': regulation of $\mathrm{RHO}$ GTPases by RHOGDIs. Nat Rev Mol Cell Bio. 2011;12:493-504.

40. Yang $Y X, H u H D$, Zhang DZ, Ren $H$. Identification of proteins responsible for the development of adriamycin resistance in human gastric cancer cells using comparative proteomics analysis. BMB Rep. 2007;40:853-60.

41. Li G, Chang M, Jiang H, Xie H, Dong Z, Hu L. Proteomics analysis of methylglyoxal-induced neurotoxic effects in SH-SY5Y cells. Cell Biochem Funct. 2011;29:30-5.

\section{Submit your next manuscript to BioMed Central and we will help you at every step:}

- We accept pre-submission inquiries

- Our selector tool helps you to find the most relevant journal

- We provide round the clock customer support

- Convenient online submission

- Thorough peer review

- Inclusion in PubMed and all major indexing services

- Maximum visibility for your research

Submit your manuscript at www.biomedcentral.com/submit
) Biomed Central 